\title{
How unprecedented was the February 2021 Texas cold snap?
}

\author{
James Doss-Gollin David J. Farnham Upmanu Lall \\ Vijay Modi
}

May 18, 2021

The following PDF contains the preprint for the paper "How unprecedented was the February 2021 Texas cold snap?."

1. The paper has now been published in Environmental Research Letters and is available open access at the following DOI: 10.1088/17489326/ac0278. This document is therefore out of date.

2. Research codes are available in a live repository at github.com/jdossgdllin/ 2021-TXtreme/. 


\title{
How unprecedented was the February 2021 Texas cold snap?
}

\author{
James Doss-Gollin ${ }^{1}$, David J. Farnham ${ }^{2}$, Upmanu Lall, ${ }^{3,4}$ and \\ Vijay Modi ${ }^{5}$ \\ ${ }^{1}$ Department of Civil and Environmental Engineering, Rice University, Houston, \\ TX, USA (ORCID 0000-0002-3428-2224) \\ 2 Department of Global Ecology, Carnegie Institution for Science, Stanford, CA, \\ USA (ORCID 0000-0002-6690-4251) \\ ${ }^{3}$ Columbia Water Center, Columbia University, New York, NY, USA (ORCID \\ 0000-0003-0529-8128) \\ ${ }^{4}$ Department of Earth and Environmental Engineering, Columbia University, New \\ York, NY, USA \\ ${ }^{4}$ Department of Mechanical Engineering, Columbia University, New York, NY, USA \\ (ORCID 0000-0003-2513-0437) \\ E-mail: jdossgollin@rice.edu
}

\begin{abstract}
Winter storm Uri brought severe cold to the southern United States in February 2021, causing a cascading failure of interdependent systems in Texas where infrastructure was not adequately prepared for such cold. In particular, the failure of interconnected energy systems restricted electricity supply just as demand for heating spiked, leaving millions of Texans without heat or electricity, many for several days. This motivates the question: did historical storms suggest that such temperatures were known to occur, and if so with what frequency? We compute a temperature-based proxy for heating demand and use this metric to answer the question "what would the aggregate demand for heating have been had historic cold snaps occurred with today's population?". We find that local temperatures and the inferred demand for heating per capita across the region served by the Texas Interconnection were more severe during a storm in December 1989 than during February 2021, and that cold snaps in 1951 and 1983 were nearly as severe. Given anticipated population growth, future storms may lead to even greater infrastructure failures if adaptive investments are not made. Further, electricity system managers should prepare for trends in electrification of heating to drive peak annual loads on the Texas Interconnection during severe winter storms.
\end{abstract}

Keywords: Energy, Electricity, Texas, Natural Hazards, Climate Resilience

Submitted to: Environ. Res. Lett. 


\section{Introduction}

Between February 14th and 17th, 2021, a northern air mass blanketed much of the continental United States, causing anomalously low surface temperatures across the Great Plains. The state of Texas was particularly hard hit, with coincident and cascading failures of natural gas production, power generation, transportation, and water systems leaving millions of Texans without electricity, heat, and water, many for several days $[1,2,3]$. These failures disproportionately affected vulnerable populations [4], left at least 111 Texans dead [5], and brought the Texas electricity grid within minutes of collapse [6].

Since production and distribution of electricity is possible under conditions far colder than any Texas experienced in February 2021, energy system failures reflect inadequate preparedness for cold. These failures occurred both because electricity demand exceeded projections, and because electricity supply failed to meet them. On the demand side, the Electric Reliability Council of Texas (ERCOT), which operates the Texas Interconnection bulk electric power system (hence "Texas Interconnection"), estimated that the peak demand would have been $76819 \mathrm{MW}$ without load shedding [6]. This surpassed ERCOT's "extreme winter forecast" of $67208 \mathrm{MW}$ in its seasonal assessment of resource adequacy [7]. On the supply side, the Texas Interconnection experienced over $30000 \mathrm{MW}$ of lost output for two consecutive days due to outages and derates caused by cold temperatures [8]. A large fraction of this supply shortfall, which exceeded ERCOT's worst-case scenario for forced outages, originated in the natural gas supply chain $[8,3,1]$.

If temperatures experienced in the region served by the Texas Interconnection were unprecedented, then this event might prompt discussion about the appropriate use of models to prepare for events that are theoretically possible, but beyond the observational record. On the other hand, historical precedent for such temperatures would suggest a broader lack of institutional and infrastructural readiness. It is therefore important to assess whether historical data offered a precedent for the temperatures observed during February 2021.

To answer this question, we first compute the population weighted difference between observed temperatures and a standard indoor temperature of $65^{\circ} \mathrm{F}$ as a proxy for the unknown heating demand, then use standard statistical procedures to assess the probability with which the temperatures observed during February 2021 might have been expected to occur a priori. We then supplement this with a spatially distributed analysis of how unexpected the cold experienced by local roads, water mains, gas pipelines, energy generation facilities, and critical infrastructure installations was across Texas. We conclude by discussing the implications of these findings for long-term electricity systems planning given anticipated population growth and electrification. 


\subsection{Previous Cold Snaps in Texas}

Texas state climatologist John Nielsen-Gammon wrote in 2011 that "winter weather is a danger to TX in part because it is so rare," [9]. Previous cold snaps in Texas, notably in 1899, 1951, 1983, 1989, and 2011 (see fig. 1 and supplemental fig. S1), have affected both human and ecological systems. For example, the 1951 cold event caused a significant die-off of fish life in the shallow Gulf Coast [10].

The specific spatiotemporal structure of a cold event, and its correspondence with population centers, determines the grid-wide demand for heating (see section 2.2). The structure of the storm also drives the aggregated hazard to energy infrastructure, which has implications for the costs and benefits of infrastructure hardening. The spatiotemporal patterns of historical cold snaps in Texas are illustrated in fig. 1 and supplemental figs. S1 and S2. Although the spatiotemporal structure of each event is distinct, it is apparent that cold extremes in Texas tend to co-occur with cold temperatures across much of the United States, particularly the Great Plains. While the 2021 event was severe, daily temperature extrema in Texas appear qualitatively comparable to historical events. The "Great Blizzard" of February 1899, shown in supplemental fig. S1, caused even more intense cold.

\section{Data and Methods}

We use three distinct datasets to analyze temperature minima in the region covered by the Texas Interconnection through the lens of distributed (each grid cell analyzed separately) and aggregated (weighted averages taken across space) extreme values analysis.

\subsection{Datasets}

We use three temperature datasets to ensure robust findings:

(i) Hourly $2 \mathrm{~m}$ air temperature reanalysis on a $0.25^{\circ}$ grid from the ERA-5 reanalysis project produced by the European Centre for Medium Range Weather Forecasting [11] and available from the Copernicus Data Store (https://cds.climate. copernicus. eu) from 1950 to the present. The period from 1950 to 1979 is released as a preliminary back extension. All plots shown in the main text use the ERA-5 data, but supplemental figures use other data sets.

(ii) Daily mean, minimum and maximum temperatures, gridded to $1^{\circ}$, produced by Berkeley Earth (http://berkeleyearth.org/data/). This gridded product is based on statistical analysis of station data and is available from 1880 to 2019. This dataset is considered an experimental product, so we use it only for comparative purposes.

(iii) To complement blended gridded data products, we use station temperature data from the Global Historical Climatology Network (GHCN) dataset compiled by the 

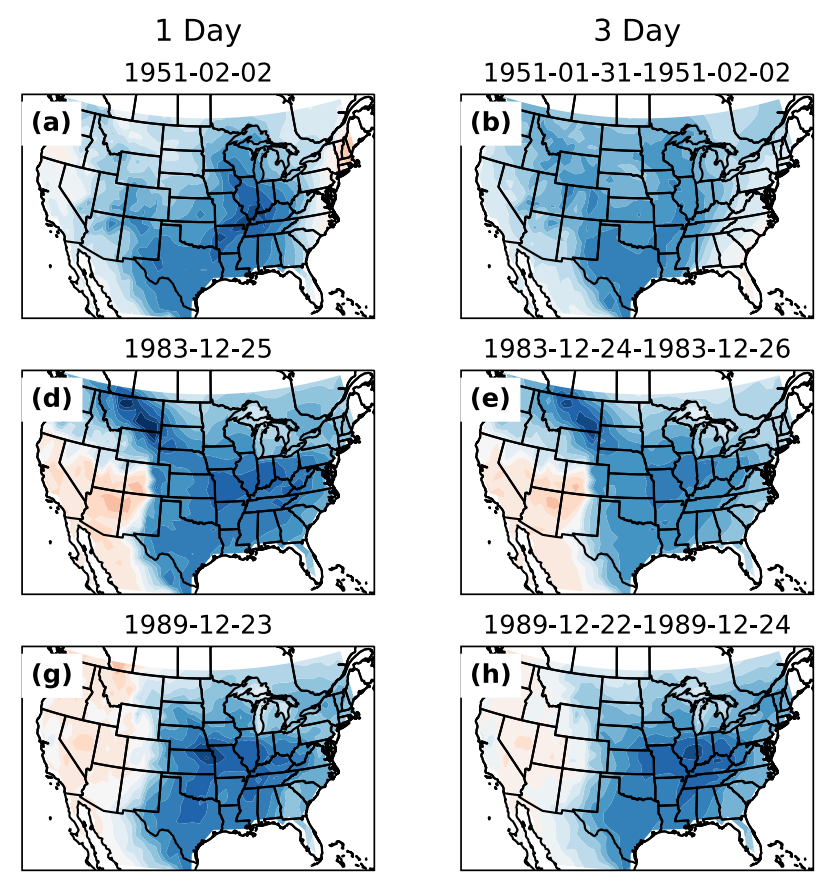

1989-12-22-1989-12-24
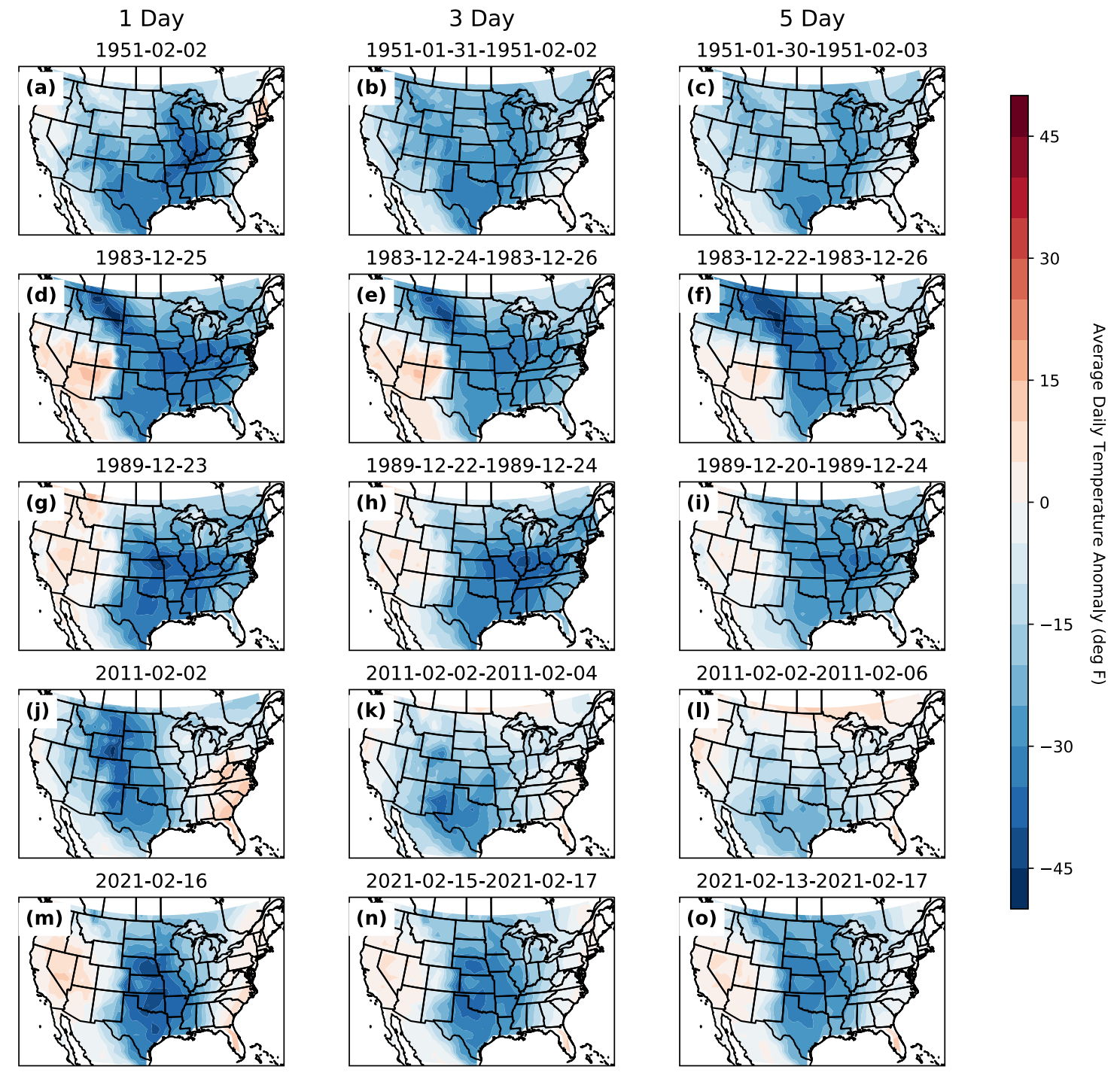

Figure 1. Severe cold snaps that affect Texas and extend into the central United States have several precedents in the historical record. Plot shows anomalies of daily mean temperatures from the ERA-5 reanalysis [11] for historic major cold events affecting Texas, defined as the departure from the seasonal (December-February) mean of the observational record. Anomalies facilitate identification of large-scale weather patterns superimposed on long-term climatological averages. Hourly temperatures are averaged to 1-day $(\mathrm{a}, \mathrm{d}, \mathrm{g}, \mathrm{j}, \mathrm{m}), 3$-day $(\mathrm{b}, \mathrm{e}, \mathrm{h}, \mathrm{k}, \mathrm{n})$, and 5 -day $(\mathrm{c}, \mathrm{f}, \mathrm{i}, \mathrm{l}, \mathrm{o})$ average temperature anomalies. 
National Ocean and Atmospheric Administration [12] and available at https:// www1.ncdc.noaa.gov/pub/data/ghcn/daily/. This dataset provides daily mean, maximum, and minimum temperature observations. These measurements represent point measurements, which can differ in important ways from gridded products describing spatial averages due to the spatial heterogeneity of temperature fields. We retain stations within the state of Texas if they provide at least 60 years of data and if they contain observations for the set of historical cold extremes shown in fig. 1 .

We also use population density data from the GPWv4 dataset [13], a list of power generation facilities from the US Energy Information Administration [14], and a map of the Texas Interconnection [15].

\subsection{Inferred heating demand per capita}

Most space heating in Texas is either electric or gas [16] and the majority of power generation in the Texas Interconnection depends on natural gas [17]. Stress on natural gas production and delivery was therefore just as important as the more visible stress on the electric system [8].

The hourly or daily thermal energy requirement for space heating is primarily driven by how much lower the ambient temperature is than an indoor comfort temperature of $65^{\circ} \mathrm{F}$. This relationship is often expressed in terms of heating degree days or hours. We therefore consider the difference between observed temperatures and a standard indoor temperature of $65^{\circ} \mathrm{F}$ as a proxy for thermal heating demand. We compute this value each hour for the ERA5 data, defining heating demand at each grid cell as $\mathrm{HD}_{t}=\max \left(65-T_{t}, 0\right)$, where $T_{t}$ is the temperature at hour $t$ in ${ }^{\circ} \mathrm{F}$. The Berkeley Earth and GHCN datasets provide daily minimum and maximum temperatures, so we define heating demand at each grid cell or station as $\mathrm{HD}_{d}=\max \left(65-\frac{T_{\min , d}+T_{\max , d}}{2}, 0\right)$, where $T_{\min , d}$ is the minimum temperature recorded on day $d$ and $T_{\max , d}$ is the maximum temperature recorded on day $d$, both in ${ }^{\circ} \mathrm{F}$.

To assess how spatially correlated cold spells might affect the Texas electric grid, we average heating demand in space over the Texas Interconnection domain [15], weighting each grid cell by 2020 population density [13]. We refer to this spatially aggregated time series, which has the straightforward interpretation as the average heating demand experienced by a Texas resident, as "inferred heating demand per capita."

\subsection{Return Period}

Return periods define the probability with which a particular event can be expected to occur. By definition, an event with return period $T$ years has a $\frac{1}{T}$ probability of occurring in a given year.

For each event duration considered, we calculated return periods by fitting a stationary generalized extreme value (GEV) distribution to the time series of annual 
maxima of inferred heating demand per capita (in section 3 ) or to the time series of $-T$, where $T$ is temperature (section 4). This negative value is analyzed because the GEV distribution is justified for block maxima, but we analyze annual minimum temperatures in section 4. Events that occur in December are coded to the following year so that a single December-February winter season is grouped together. The 2021 winter season was excluded from return period estimates, allowing us to interpret return periods for the February 2021 event as a priori estimates.

\subsection{Cold Duration}

The effect of cold temperatures on energy demand and critical infrastructure depends on how long the cold persists. Short duration cold snaps can kill plants, freeze exposed pipes, freeze wind turbines, and contribute to dangerous roadway conditions. Longer duration cold spells contribute to demand for heating and energy and cause pipes to burst even if they have some insulation. We calculate demand for heating by taking temporal averages over a range of durations from 1 hour to 4 days.

\subsection{Code and Data}

We are committed to open science. Our open source code is freely available in a live repository at https://github.com/jdossgollin/2021-TXtreme and in an archived repository at https://dx.doi.org/10.5281/zenodo. 4739881 .

\section{How extreme was inferred heating demand per capita over the Texas Interconnection?}

The total shock to Texas heating demand is partially determined by the extent to which cold snaps impact multiple population centers simultaneously. As such, understanding whether there was precedent for a cold snap simultaneously affecting several regions of Texas's grid that today have high population density is critical. We therefore use our measure of inferred heating demand per capita (see section 2.2) to represent the aggregate heating demand induced by cold temperatures. Aggregating historic temperature fields in space using the 2020 population, we answer the question "what would the aggregate demand for heating have been had historic cold snaps occurred today?"

Figure 2 shows that the intensity, duration, and recurrence intervals of the February 2021 storm are severe but not unprecedented in the historical record. For example, at the 6 hour duration the December 1989 storm was substantially more intense and other storms including February 1951 were nearly as intense. At the two day duration, the 2021 and 1989 events were approximately equally intense and other storms including December 1983 were nearly as intense. The 2011 storm, which caused rolling blackouts and motivated research into the energy system's vulnerability to cold [18], was quite 

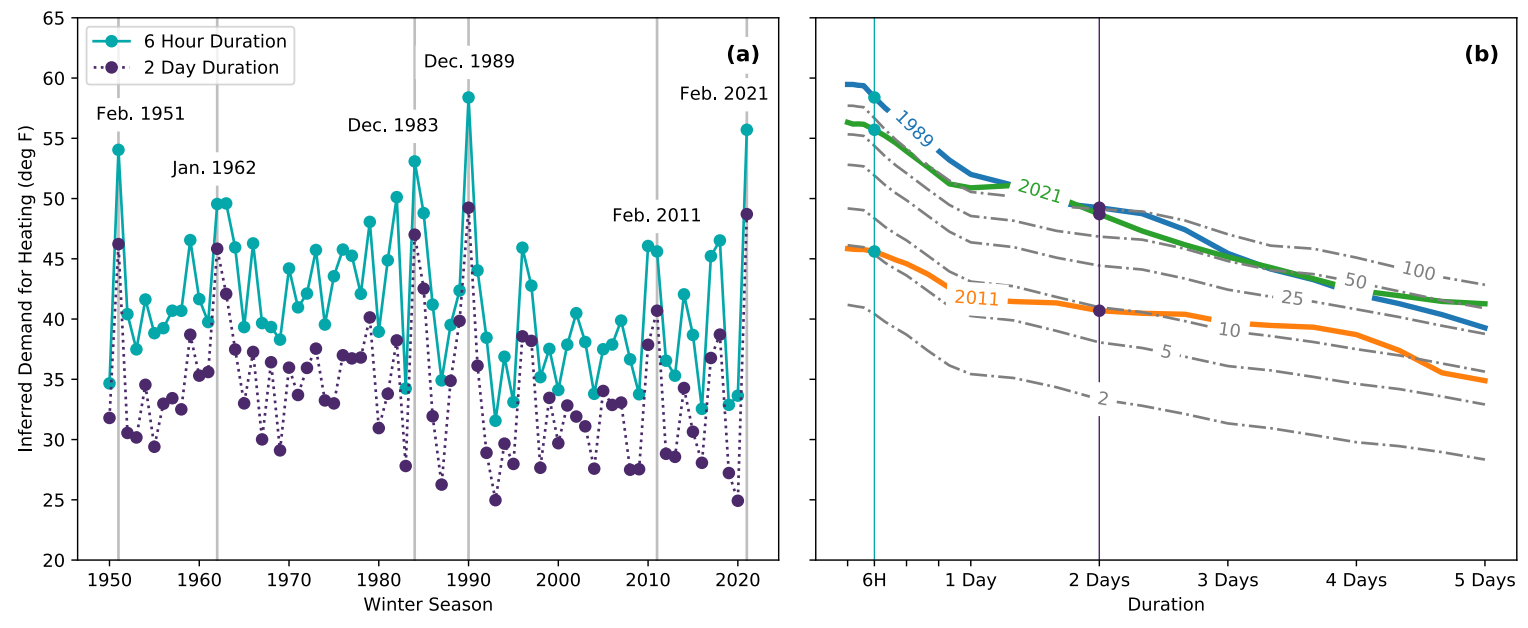

Figure 2. The inferred heating demand per capita induced by the February 2021 cold snap is not unprecedented. For the worst 6 hours, the 1989 event was more severe than the 2021 event, while they are comparable for longer durations. (a): time series of annual maximum inferred heating demand per capita (section 2.2) at 6 hour and 2 day durations. December extremes, including the December 1989 storm, are coded to the following year so that one maximum per December-February winter season is taken. (b): the intensity-duration-frequency intervals estimated using 1950-2020 data (i.e., not using the 2021 event), overlaid by the annual maxima from the 1989, 2011, and 2021 events. Gray dashed lines indicate 2, 5, 10, 25, 50, and 100 year return levels.

modest by comparison. The right panel shows statistical return periods for these extreme events.

\section{Spatially distributed temperature extremes}

It is difficult to establish a spatially aggregated proxy for supply-side risk given complex interlinkages between natural gas, electric, and other systems which create the possibility for cascading failures as observed in February 2021. Water treatment and distribution systems, as well as other essential services, also rely on electricity, further increasing vulnerabilities. Instead of aggregating this risk in space, we estimate the exceedance probability of the February 2021 temperatures at each grid cell separately to shed light on the severity of cold experienced by installations across the region.

Figure 3 shows local return periods for February 2021 temperature at 6 hour, 1 day, 2 day, and 4 day durations. Other than a band from south-central to south-east Texas, nearly all regions of the Texas Interconnection (gray outline in fig. 3a,d) experienced cold with a return period below 50 years. Results are similar using station data (supplemental fig. S3). Importantly for the energy system, the band experiencing cold with return period greater than 50 years includes a substantial fraction of Texas's population (fig. 3a) and natural gas generation (fig. 3d). Outside the Texas Interconnection region, the Midcontinent Independent System Operator and Southwest Power Pool instructed utilities to shed firm load. Yet despite local return periods for temperature in central 


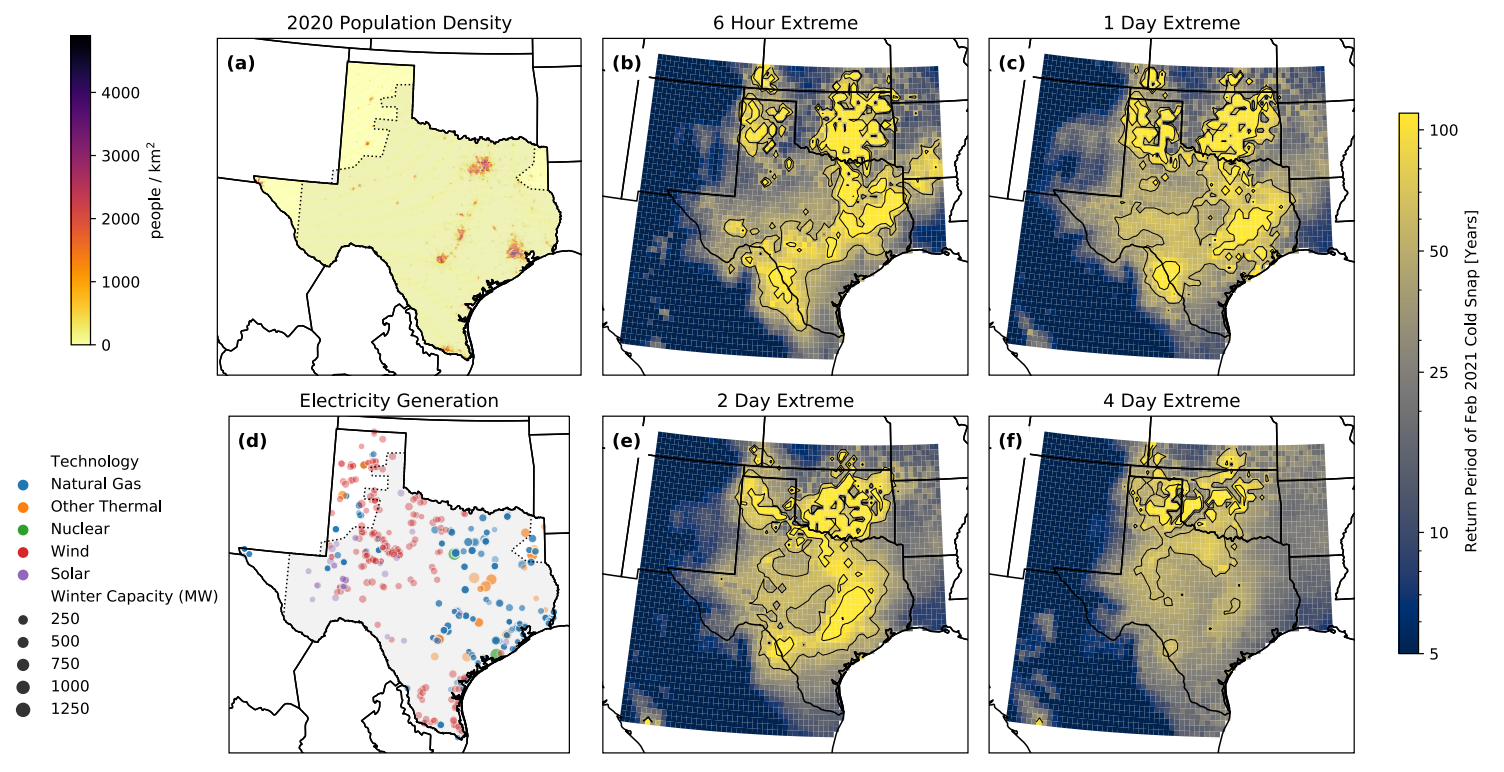

Figure 3. Return periods for the February 2021 event, calculated using stationary estimates of annual extremes over the period 1950-2020. Return periods are calculated separately for each cell. (a): estimates of 2020 population density [13]. (d): energy generation facilities in Texas [14]. (b,c,e,f): local return periods for 6 hour, 1 day, 2 day, and 4 day durations, respectively. Contours enclose regions that recorded 50 and 100 year return levels. The gray region in panels (a) and (d) shows boundaries of the Texas Interconnection [15].

Oklahoma equal to or greater than local return periods for temperature in Texas, $92 \%$ of the customers in Texas, Louisiana, and Oklahoma without power were in Texas [1].

\section{Discussion}

Our spatially aggregated metric of inferred heating demand per capita shows that the February 2021 event was intense but not without precedent in the histoircal record (fig. 2). Although specific locations experienced very intense (>100 year return period) temperatures, we find that for most locations in Texas the temperatures recorded during the February 2021 cold snap had precedent in the historical record.

A proximate cause of load shedding in the Texas Interconnection during February 2021 was the vulnerability of the electricity generation system to cold [17]. As shown in supplemental fig. S8, generator outages occurred across the state, even though most parts of the state had previously experienced similarly intense cold, notably in 1989 (fig. 3 and supplemental fig. S3). Yet despite temperatures that were, in aggregate, more intense, the Texas Interconnection experienced fewer than three hours of rolling blackouts from December 21-23, 1989 [19, 20]. Following the 1983, 1989, and 2011 cold snaps, the North American Electric Reliability Corporation (NERC) identified "constraints on natural gas fuel supplies to generating plants" and "generating unit trips, derates, or failure to start due to weather related causes" as key vulnerabilities 
[21], foreshadowing many of the causes of February 2021 energy system failures identified by ERCOT $[8,6]$. While our analysis neglects other meteorological factors, like freezing rain, that may have impeded operations at specific facilities, we find that the February 2021 failures of energy and electricity systems in the Texas Interconnection took place during temperatures with precedent in the historical record.

Another cause of load shedding was the high demand for electricity that low temperatures induced. In fact, around $55 \%$ of both residential and commercial spaces in Texas are currently heated using electricity [16] and further electrification is a central element of many plans to decarbonize the energy sector [22, 23, 24]. While summer peak loads have been a central planning concern on the Texas grid in the past, it is likely that winter peak loads will become a greater concern in the coming decades. In fact, the estimated $76819 \mathrm{MW}$ of peak demand without load shedding during this event [6] exceeded not only the previous winter demand record of $65900 \mathrm{MW}$ recorded on January 17, 2018 but also the all-season record actual demand of $74800 \mathrm{MW}$ recorded on August 19, 2019 [17]. As electrification of heating continues, severe cold snaps may drive peak demands on the Texas Interconnection.

Our primary findings hold for an alternative gridded dataset and station data (see supplemental material). However, calculated return periods are sensitive to the method of estimation (supplemental figs. S5 and S6). Future analysis could address parametric uncertainty, model structure uncertainty [25], non-stationarity [26], or regime-like modes of climate variability [27]. More fundamentally, an assessment of exposure to cold extremes over the next decades should consider the deeply uncertain distribution of future climate change, and the induced effect on cold extremes in Texas. Although a broad scientific consensus suggests the frequency of cold extremes should decrease under warming in most places [28], possible links between North-South temperature gradients and mid-latitude temperature extremes remains an area of active research $[29,30,31,32]$. Regardless, the effect of climate change on peak demand for heating is likely to be small compared to the effect of rapid population growth which the Texas Water Development Board, for example, anticipates to be 40\% from 2020 to 2050 [33].

Our analysis quantifies the frequency with which the temperatures observed during February 2021 could have been expected to occur a priori. Other factors also govern infrastructure performance and failure, including precipitation, the demand for natural gas in adjacent regions, and complex connections within and between regional systems. Similarly, decisions at multiple time scales, including disaster preparedness and risk communication, contribute to the human consequences of physical infrastructure failure. Thus, the exact chain of events that led to the blackouts and water system disruptions during February 2021 should be sorted out only after further investigations by parties on the ground in Texas. 


\section{Conclusions}

The February 2021 cold snap was the most intense in 30 years, but was not without precedent in the full historical record. In addition to the record cold conditions of 1899 (supplemental fig. S1), we estimate that the weather of December 1989 would have resulted in higher 6-hour and 2-day values of inferred heating demand per capita over the Texas Interconnection than the February 2021 event. Storms in February 1951, January 1962, and December 1983 would have resulted in at least 90\% as much inferred heating demand per capita at 24 and 48 hour durations. Given upward trends in the electrification of heating, it is likely that future cold snaps will cause peak annual loads on the Texas Interconnection to occur during the winter season. Infrastructure expansion necessitated by a rapidly growing population offers Texas the opportunity to invest in a more resilient energy system.

\section{Acknowledgements}

DJF was supported by a gift from Gates Ventures LLC to the Carnegie Institution for Science. The authors thank Daniel Cohan, Sylvia Dee, Elisabeth Gawthrop, Pedram Hassanzadeh, Fred Heutte, Adam Massmann, Alison Silverstein, Vivek Srikrishnan, and Edgar Virgüez for discussion of this work. The authors also thank the developers and maintainers of the open source packages we used, in particular the pydata and pangeo communities, and the many journalists and academics whose timely reporting and commentary has informed our thinking.

\section{Bibliography}

[1] CESER. Extreme cold \& winter weather update \#1. Technical report, U.S. Department of Energy Office of Cybsersecurity, Energy Security, and Emergency Response, February 2021.

[2] Christopher T. M. Clack, Aditya Choukulkar, Brianna Coté, and Sarah A McKee. ERCOT winter storm Uri blackout analysis (February, 2021). Technical report, Vibrant Clean Energy, LLC, March 2021.

[3] Richard G. Smead. ERCOT-the eyes of Texas (and the World) are upon you: What can be done to avoid a February 2021 repeat. Climate and Energy, 37(10):14-18, 2021.

[4] James Dobbins and Hiroko Tabuchi. Texas blackouts hit minority neighborhoods especially hard. The New York Times, February 2021.

[5] Shawn Mulcahy. At least 111 people died in Texas during winter storm, most from hypothermia. The Texas Tribune, March 2021.

[6] Bill Magness. Review of February 2021 extreme cold weather event, February 2021.

[7] ERCOT. Final seasonal assessment of resource adequacy for the ERCOT region (SARA): Winter 2020/2021. Technical report, Electric Reliability Council of Texas, November 2020.

[8] ERCOT. Update to April 6, 2021 preliminary report on causes of generator outages and derates during the February 2021 extreme cold weather event. Technical report, Electric Reliability Council of Texas, April 2021.

[9] John W. Nielsen-Gammon. The Changing Climate of Texas. University of Texas Press, June 2011. 
[10] Gordon Gunter. Destruction of fishes and other organisms on the South Texas Coast by the cold wave of January 28-February 3, 1951. Ecology, 32(4):731-736, 1951.

[11] Hans Hersbach, Bill Bell, Paul Berrisford, Shoji Hirahara, András Horányi, Joaquín MuñozSabater, Julien Nicolas, Carole Peubey, Raluca Radu, Dinand Schepers, Adrian Simmons, Cornel Soci, Saleh Abdalla, Xavier Abellan, Gianpaolo Balsamo, Peter Bechtold, Gionata Biavati, Jean Bidlot, Massimo Bonavita, Giovanna De Chiara, Per Dahlgren, Dick Dee, Michail Diamantakis, Rossana Dragani, Johannes Flemming, Richard Forbes, Manuel Fuentes, Alan Geer, Leo Haimberger, Sean Healy, Robin J. Hogan, Elías Hólm, Marta Janisková, Sarah Keeley, Patrick Laloyaux, Philippe Lopez, Cristina Lupu, Gabor Radnoti, Patricia de Rosnay, Iryna Rozum, Freja Vamborg, Sebastien Villaume, and Jean-Noël Thépaut. The ERA5 global reanalysis. Quarterly Journal of the Royal Meteorological Society, 146(730):1999-2049, 2020.

[12] Matthew J Menne, Imke Durre, Russell S Vose, Byron E Gleason, and Tamara G Houston. An overview of the global historical climatology network-daily database. Journal of Atmospheric and Oceanic Technology, 29(7):897-910, July 2012.

[13] CIESIN. Gridded population of the world, version 4 (GPWv4): Population density. Technical report, Center for International Earth Science Information Network - CIESIN - Columbia University, Palisades, NY, 2016.

[14] USEIA. Preliminary monthly electric generator inventory (based on Form EIA-860M as a supplement to Form EIA-860), November 2021.

[15] USEIA. North American Electric Reliability Corporation (NERC) Regions, 2021.

[16] Michael Waite and Vijay Modi. Electricity load implications of space heating decarbonization pathways. Joule, 4(2):376-394, February 2020.

[17] Keith Everhart and Gergely Molnar. Severe power cuts in Texas highlight energy security risks related to extreme weather events. Technical report, International Energy Agency, February 2021.

[18] FERC and NERC. Report on outages and curtailments during the Southwest cold weather event. Technical report, Federal Energy Regulatory Commission and North American Electric Reliability Corporation, August 2011.

[19] NERC. ERCOT emergency operation December 21-32, 1989. Technical report, North American Electric Reliability Corporation, 1989.

[20] James Osborne. A tale of two freezes: How the Texas power grid stayed on in the 1989 cold snap. Houston Chronicle, March 2021.

[21] NERC. Assessment of previous severe winter weather reports 1983-2011. Technical report, North American Electric Reliability Corporation, Atlanta, GA, July 2013.

[22] James H. Williams, Andrew DeBenedictis, Rebecca Ghanadan, Amber Mahone, Jack Moore, William R. Morrow, Snuller Price, and Margaret S. Torn. The technology path to deep greenhouse gas emissions cuts by 2050: The pivotal role of electricity. Science, 335(6064):53-59, January 2012.

[23] Steven J. Davis, Nathan S. Lewis, Matthew Shaner, Sonia Aggarwal, Doug Arent, Inês L. Azevedo, Sally M. Benson, Thomas Bradley, Jack Brouwer, Yet-Ming Chiang, Christopher T. M. Clack, Armond Cohen, Stephen Doig, Jae Edmonds, Paul Fennell, Christopher B. Field, Bryan Hannegan, Bri-Mathias Hodge, Martin I. Hoffert, Eric Ingersoll, Paulina Jaramillo, Klaus S. Lackner, Katharine J. Mach, Michael Mastrandrea, Joan Ogden, Per F. Peterson, Daniel L. Sanchez, Daniel Sperling, Joseph Stagner, Jessika E. Trancik, Chi-Jen Yang, and Ken Caldeira. Net-zero emissions energy systems. Science, 360(6396):eaas9793, June 2018.

[24] Philip M White and Joshua D Rhodes. Electrification of heating in the Texas residential sector. Technical report, IdeaSmiths, LLC, 2019.

[25] Tony E. Wong, Alexandra Klufas, Vivek Srikrishnan, and Klaus Keller. Neglecting model structural uncertainty underestimates upper tails of flood hazard. Environmental Research Letters, 13(7):074019, July 2018.

[26] P C D Milly, Julio Betancourt, M Falkenmark, R M Hirsch, Z W Kundzewicz, D P Lettenmaier, 
and R J Stouffer. Stationarity is dead: Whither water management? Science, 319(5863):573574, February 2008.

[27] James Doss-Gollin, David J. Farnham, Scott Steinschneider, and Upmanu Lall. Robust adaptation to multiscale climate variability. Earth's Future, 7(7), June 2019.

[28] IPCC. Climate change 2014: Synthesis report. Contribution of Working Groups I, II and III to the fifth Assessment report of the Intergovernmental Panel on Climate Change. Technical report, International Panel on Climate Change, Geneva, Switzerland, 2014.

[29] Elizabeth A Barnes. Revisiting the evidence linking Arctic amplification to extreme weather in midlatitudes. Geophysical Research Letters, 40(17):4734-4739, September 2013.

[30] Judah Cohen, James A Screen, Jason C Furtado, Mathew Barlow, David Whittleston, Dim Coumou, Jennifer Francis, Klaus Dethloff, Dara Entekhabi, James Overland, and Justin Jones. Recent Arctic amplification and extreme mid-latitude weather. Nature Geoscience, 7(9):627637, August 2014.

[31] James A Screen and Ian Simmonds. Exploring links between Arctic Amplification and mid-latitude weather. Geophysical Research Letters, 40(5):959-964, March 2013.

[32] Erik Romanowsky, Dörthe Handorf, Ralf Jaiser, Ingo Wohltmann, Wolfgang Dorn, Jinro Ukita, Judah Cohen, Klaus Dethloff, and Markus Rex. The role of stratospheric ozone for Arcticmidlatitude linkages. Scientific Reports, 9(1):7962, May 2019.

[33] Texas Water Development Board. Water for Texas 2012 state water plan. Technical report, January 2012. 


\title{
Supplemental Information: How unprecedented was the February 2021 Texas cold snap?
}

\author{
James Doss-Gollin ${ }^{1}$, David J. Farnham ${ }^{2}$, Upmanu Lall, ${ }^{3,4}$ and \\ Vijay Modi ${ }^{5}$ \\ 1 Department of Civil and Environmental Engineering, Rice University, Houston, \\ TX, USA (ORCID 0000-0002-3428-2224) \\ 2 Department of Global Ecology, Carnegie Institution for Science, Stanford, CA, \\ USA (ORCID 0000-0002-6690-4251) \\ 3 Columbia Water Center, Columbia University, New York, NY, USA (ORCID \\ 0000-0003-0529-8128) \\ ${ }^{4}$ Department of Earth and Environmental Engineering, Columbia University, New \\ York, NY, USA \\ 4 Department of Mechanical Engineering, Columbia University, New York, NY, USA \\ (ORCID 0000-0003-2513-0437) \\ E-mail: jdossgollin@rice.edu
}

Submitted to: Environ. Res. Lett. 
Supplemental Information: How unprecedented was the February 2021 Texas cold snap?2

\section{Supplemental Results}

\subsection{Historic Extreme Temperatures}

To complement fig. 1, we plot extreme cold temperatures using alternate data. First, fig. S1 shows historic events over the Continental United States. The set of events is slightly different than that of fig. 1: the data set does not include the 2021 event, but does include the 1899 "Great Blizzard." The 1899 event shows more intense and persistent cold than the other events in the dataset. Next, fig. S2 shows the same data as fig. 1 but zooms in on Texas. The 1989 (g-i) and 2021 (m-o) appear to be the most severe events in this data set, and the 1-day cold extremes in the 1989 event are more intense than in the February 2021 event, consistent with results in the main text.

\subsection{Spatially distributed temperature extremes}

To complement fig. 3, we compute local return periods using station data from the GHCN [12]. Figure S3 shows the return periods of the February 2021 cold snap for 1, 2, 3 , and 4 day durations. Only stations with at least 60 years of data are considered, and since the locations of these stations are not chosen at random, this does not constitute a representative sample of all points across Texas. However, the spatial pattern matches that of fig. 3, with a band of severe cold stretching from south-central to eastern Texas and in the Texas Panhandle.

\subsection{Inferred heating demand per capita}

To complement our analysis of inferred heating demand per capita, we consider how results change as a function of two modeling decisions. First, we consider what happens if the spatial field demand for heating is aggregated using grid cell area rather than population density. Next, we compute return periods using an estimator based on the method of $L$-moments. Although $L$-moment estimators for the generalized extreme value distribution are not unbiased, they are popular in the statistical hydrology literature for their stability [?, ?, ?].

We draw two conclusions from these plots. First, the 2021 event appears more severe if grid cells are weighted by population density (figs. 2 and S5) than if they are weighted only by area figs. S4 and S6). This is consistent with our observation of a correspondence between the most extreme temperatures in February 2021 and population density (fig. 3). By contrast, the 2011 event appears more extreme when grid cells are weighted by area, which is consistent with figs. 1 to S2 showing the coldest

temperatures in relatively less populated West Texas. Second, the $L$-moment estimators (figs. S5 and S6) assign a lower return period to the 1989 and 2021 events than the maximum likelihood estimators (figs. 2 and S4).

To provide some context for our inferred demand for heating metric, fig. S7 plots its time series during the peak of the February 2021 cold snap. This reveals a rise from approximately $10^{\circ} \mathrm{F}$ to nearly $60^{\circ} \mathrm{F}$ during the peak of the February 2021 cold snap. 


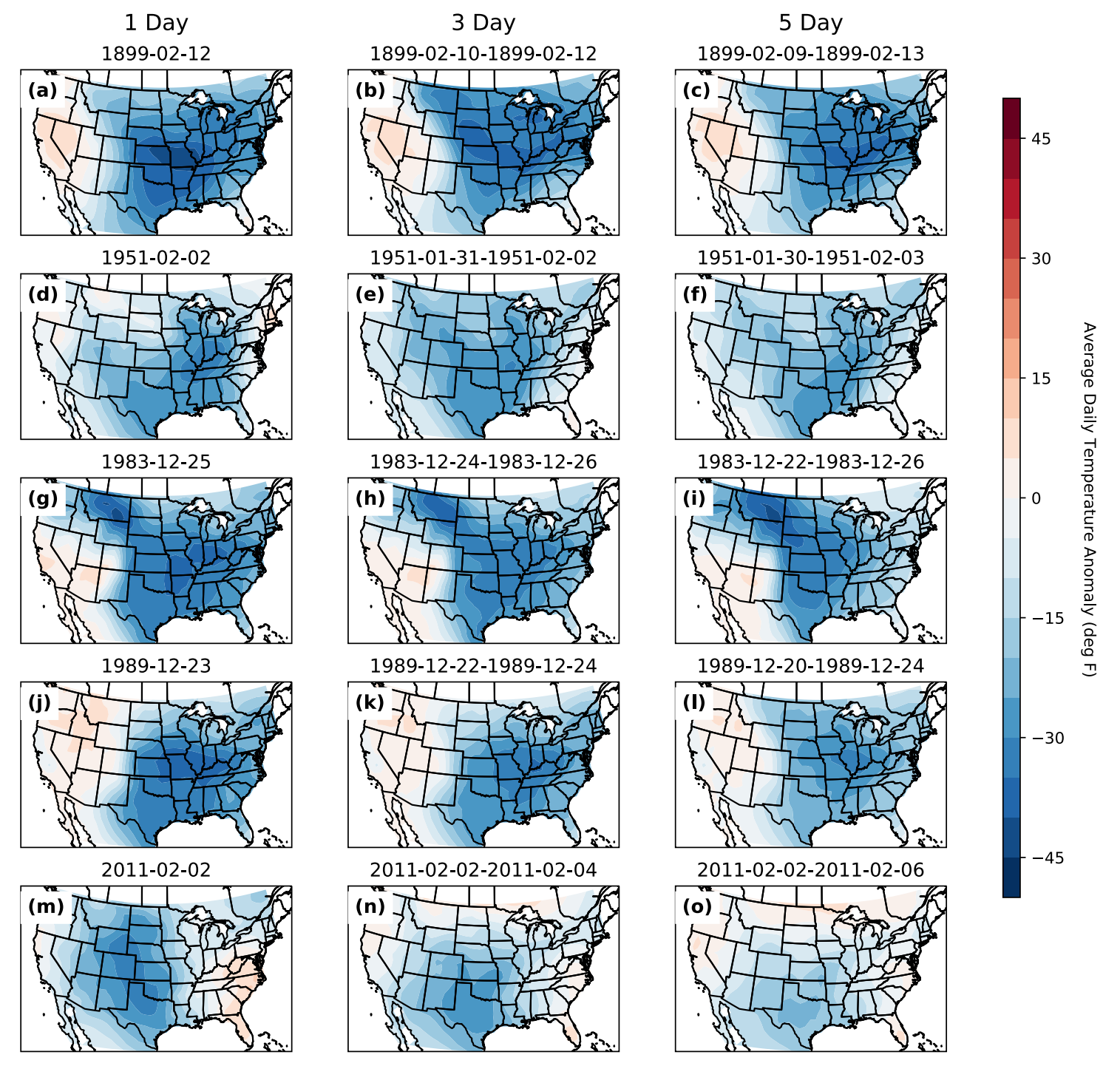

Figure S1. As fig. S1 but the Berkely Earth temperature data is used. The dataset does not contain the 2021 event, but the "Great Blizzard" of February 1899 is included. Spatial patterns of cold from this dataset are qualitatively similar to Figure 1. The 1899 event emphasizes that the modern historical record does not yield a full sample from the full distribution of possible hazards. 
1 Day

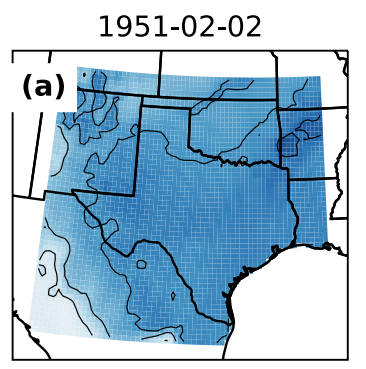

1983-12-25
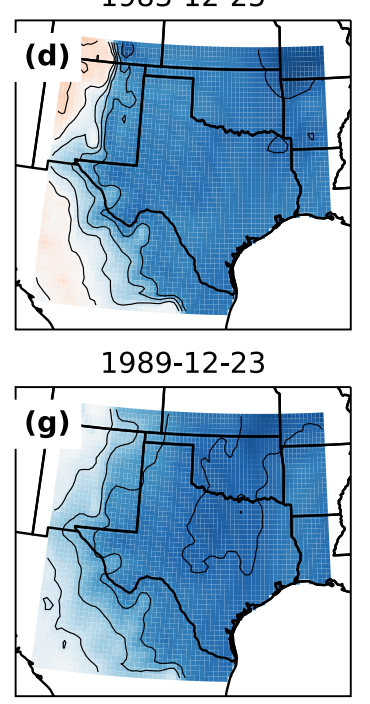

2011-02-02

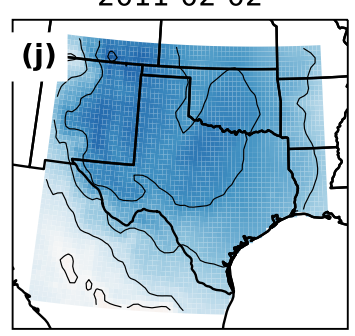

2021-02-16

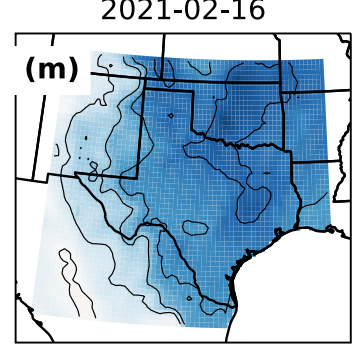

3 Day

1951-01-30-1951-02-02

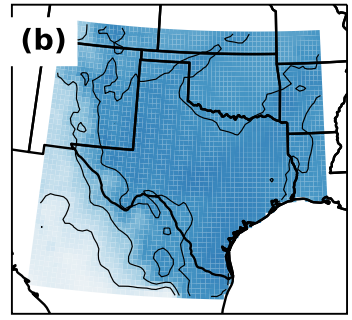

1983-12-23-1983-12-26

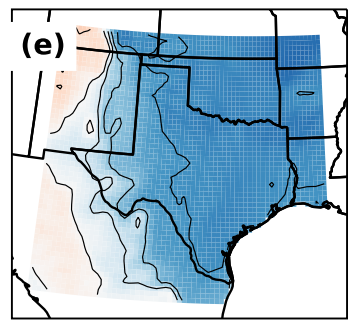

1989-12-21-1989-12-24

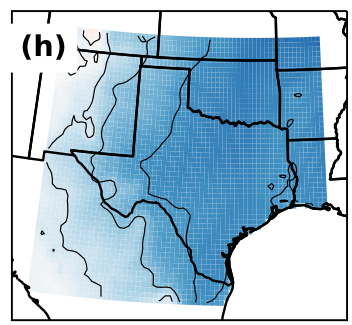

2011-02-01-2011-02-04
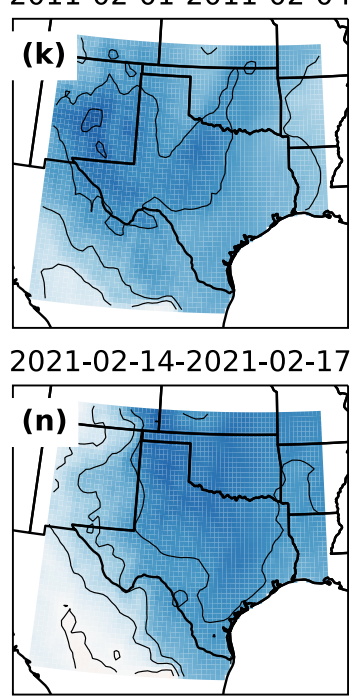

5 Day

1951-01-29-1951-02-03

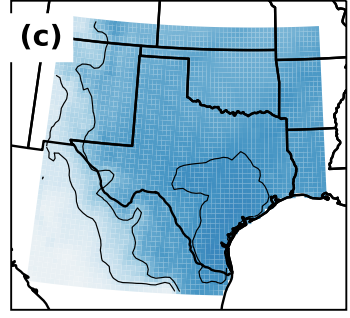

1983-12-21-1983-12-26

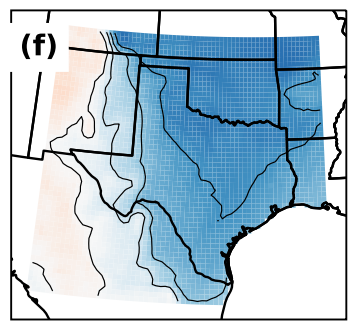

1989-12-19-1989-12-24

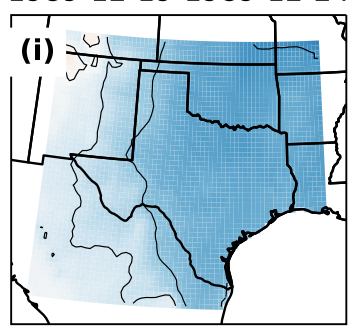

2011-02-01-2011-02-06

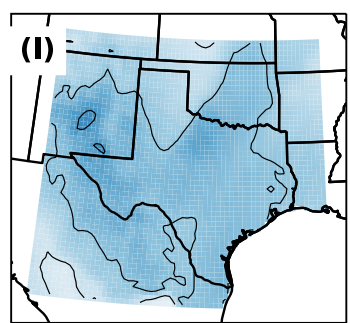

2021-02-12-2021-02-17

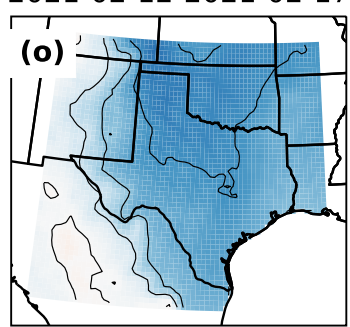

40

20

$-40$

Figure S2. As fig. S1 but only Texas is shown. 
Supplemental Information: How unprecedented was the February 2021 Texas cold snap?5
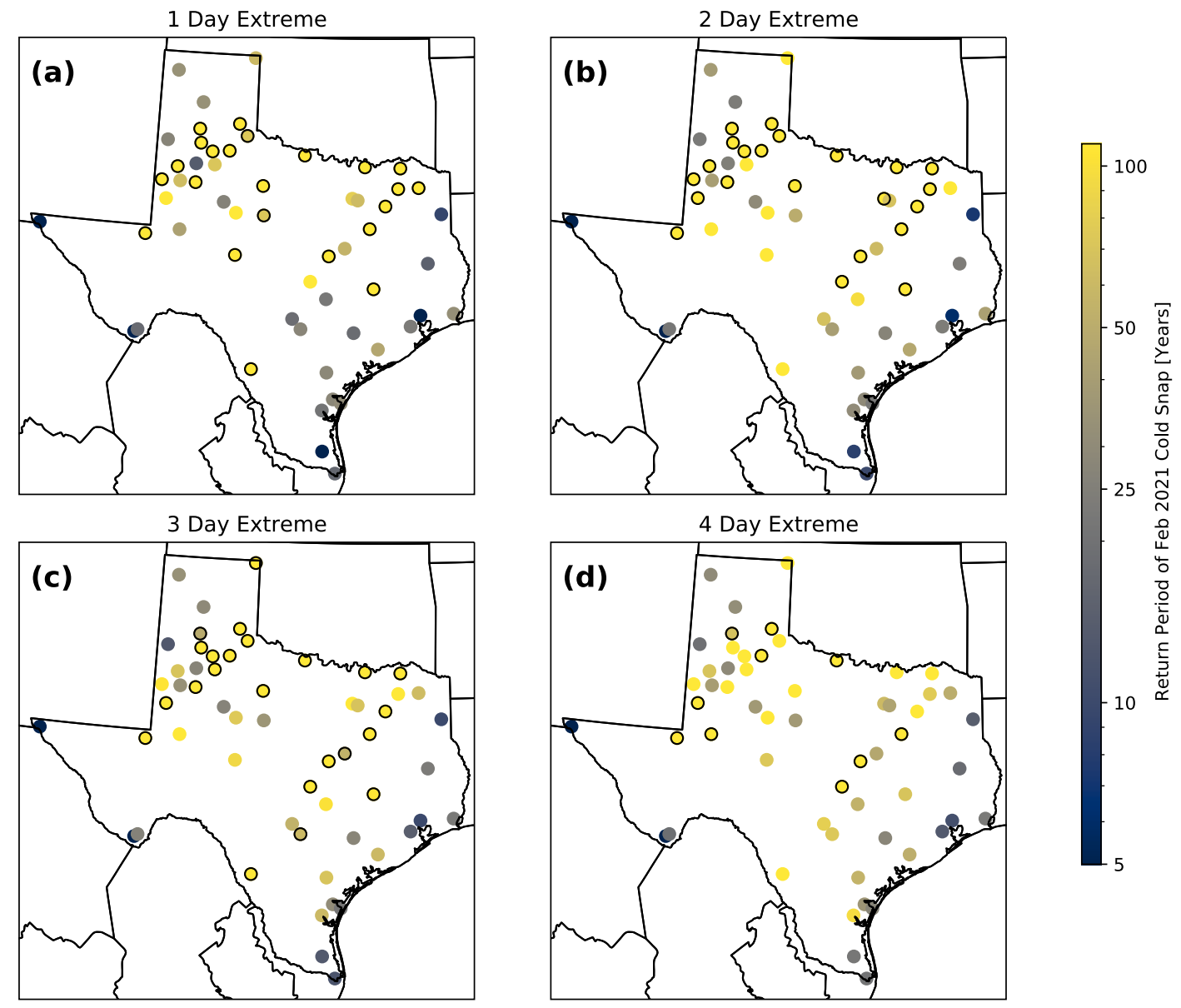

Figure S3. As fig. 3 but return periods are calculated using station data from the GHCN data set [12]. Black circles indicate that a station exceeded its own record for a particular duration.
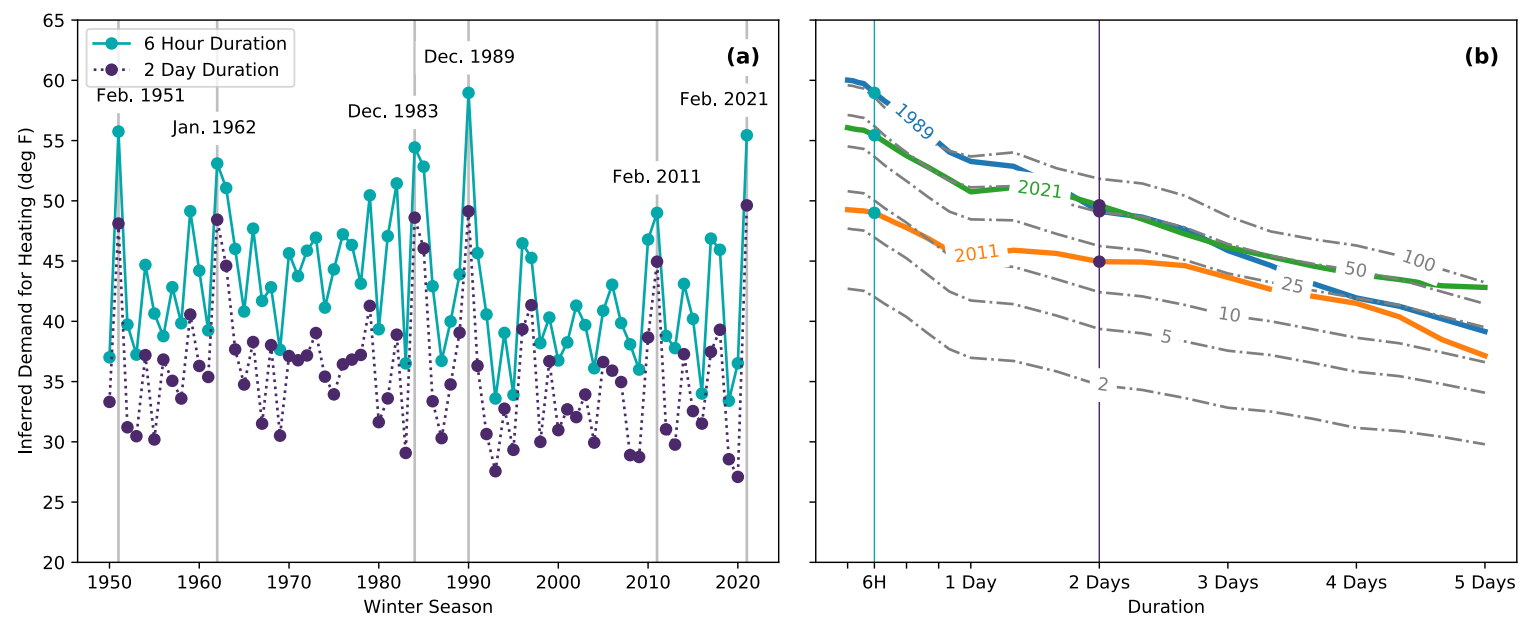

Figure S4. As fig. S4 but grid cells are weighted by area $A=\cos (\phi)$ where $\phi$ is latitude. 
Supplemental Information: How unprecedented was the February 2021 Texas cold snap?6
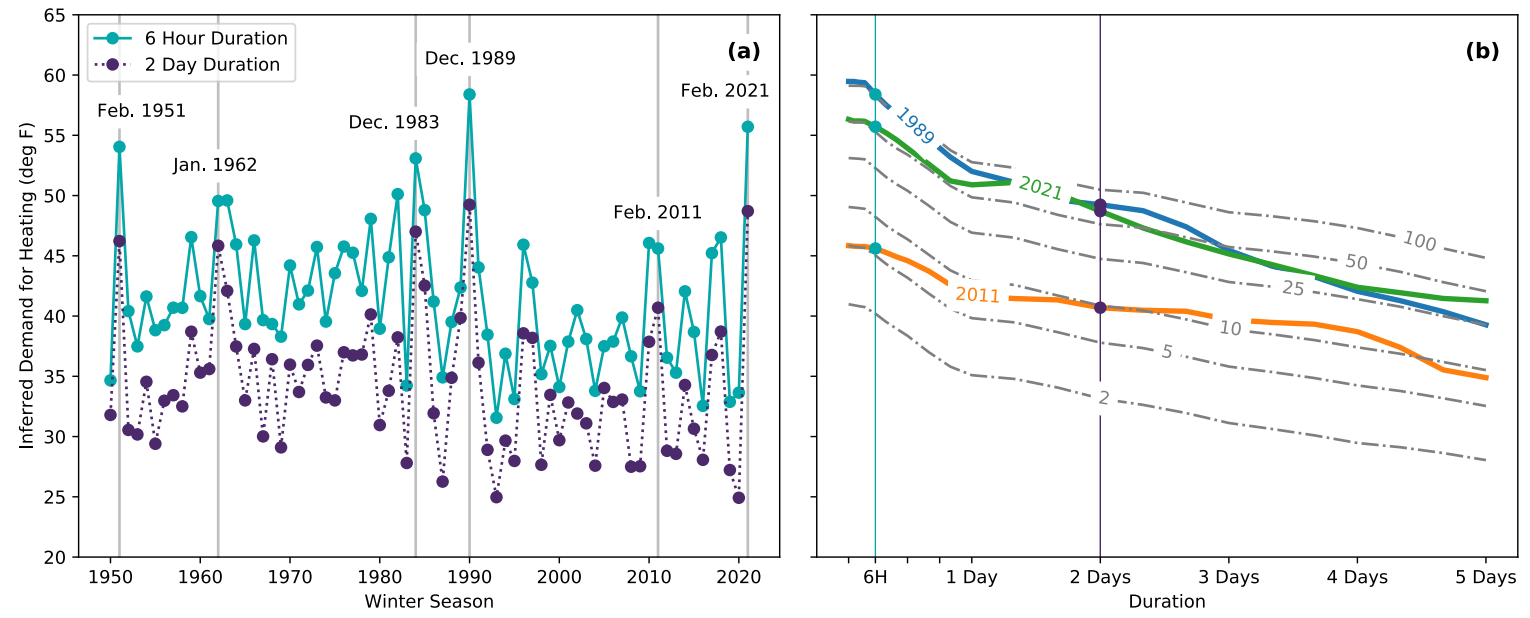

Figure S5. As fig. S4 but return periods are calculated using the $L$-moments estimator.
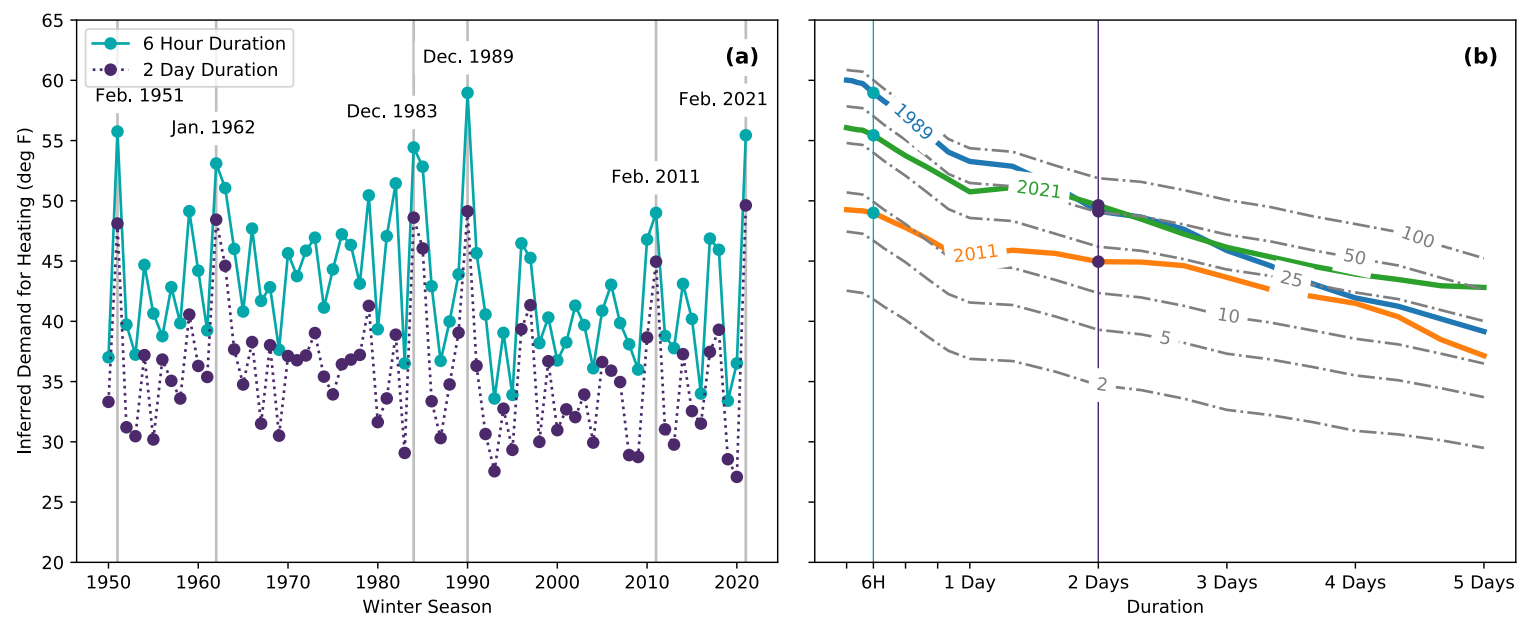

Figure S6. As fig. S4 but return periods are calculated using the $L$-moments estimator. 
Supplemental Information: How unprecedented was the February 2021 Texas cold snap?7

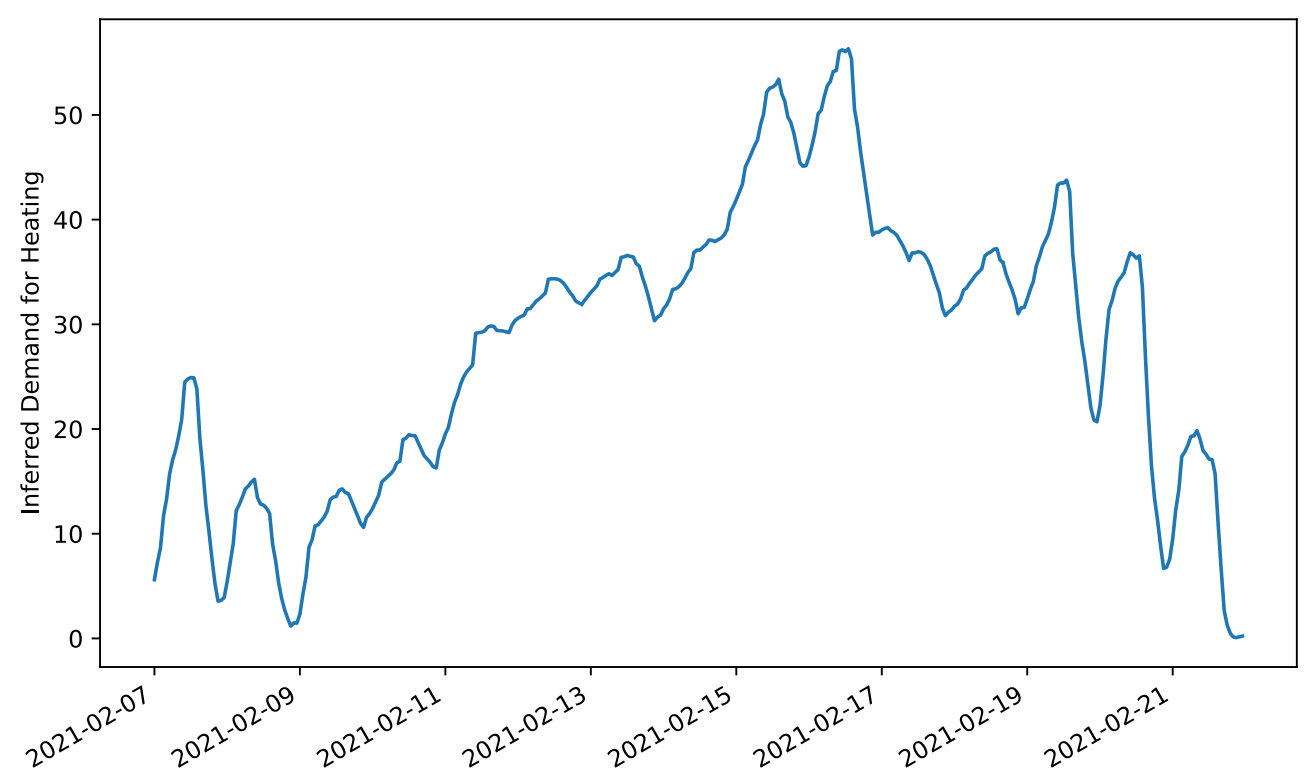

Figure S7. A time series of inferred heating demand per capita over the Texas Interconnection during the February 2021 cold snap. 
ERCOT Generator Outages 2/14/2021 12:00AM to 2/18/2021 12:00AM

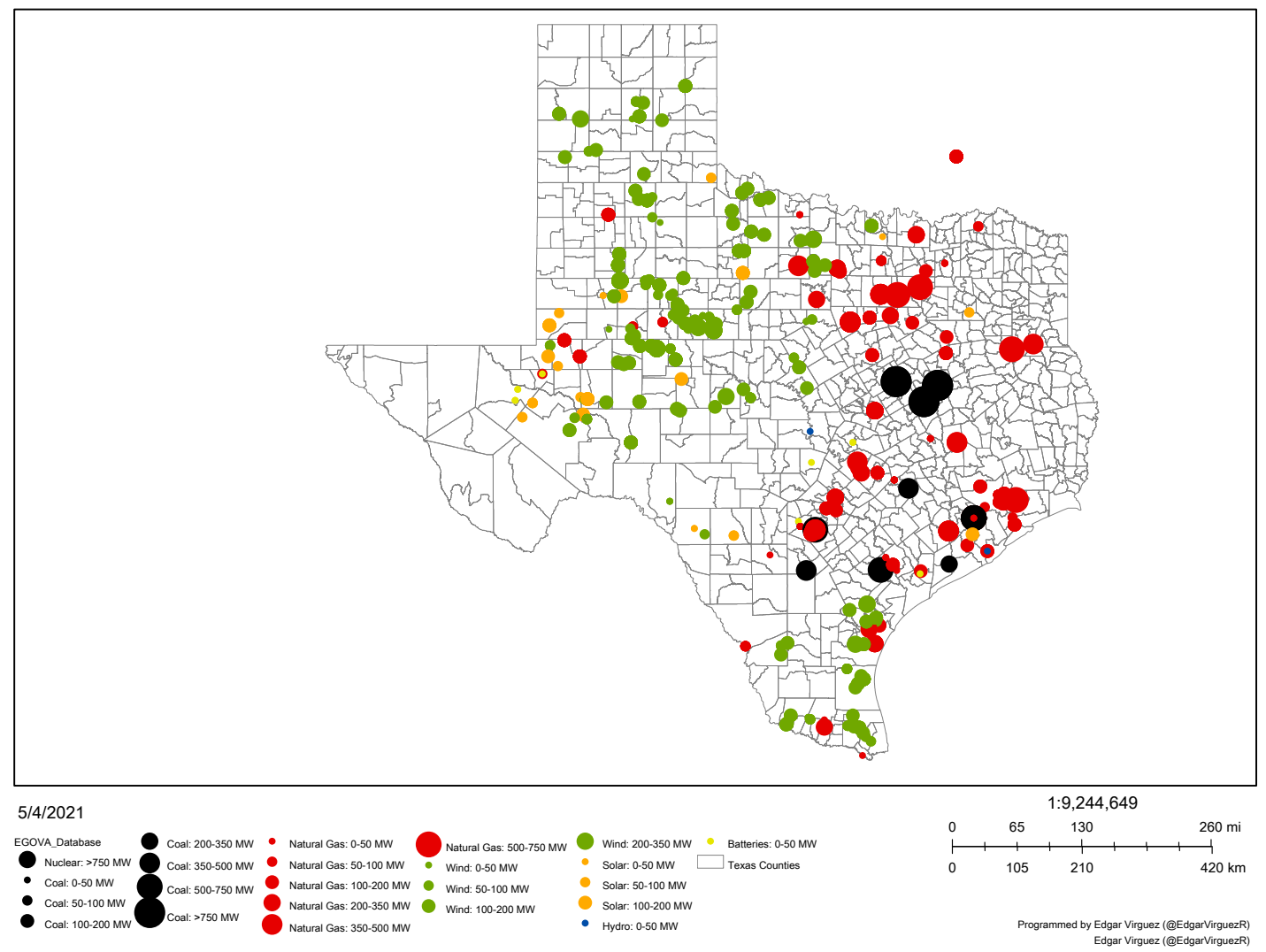

Figure S8. ERCOT generator outages from 12:00AM on 14 February 2021 to 12:00AM on 18 February 2021. Map produced using ERCOT's Generator Outage/Derate Visualization App (EGOVA) available at https://bit.1y/EGOVA. Dot sizes describe the capacity reduction for each outage or derate event, which may not be the same as the difference between the power produced and what ERCOT anticipated, particularly for intermittent resources [8]. 